\title{
RCC Highrised Residential Buildings its Influence on Earthquake Loads
}

\author{
Y. Kamala Raju ${ }^{1 *}$ G.V.V. Satyanarayana ${ }^{2}$ and G. Arun $\mathrm{Sai}^{3}$ \\ ${ }^{1}$ Assistant Professor, Civil Engg. Dept., GRIET, Hyd., India \\ ${ }^{2}$ Professor, Civil Engg., Dept., GRIET, Hyd., India \\ ${ }^{3}$ PG Scholar, Civil Engg., Dept., GRIET, Hyd., India
}

\begin{abstract}
The present decade, high rise multi-storey buildings are subjected to many external effects such as earthquake, wind loads, tidal loads, etc., in most cases high rise buildings have more vulnerable to earthquake and wind loads. Most of the reinforced concrete multi-storeyed frame buildings were heavily damaged and many of them completely collapsed during due earthquakes. RC frame buildings were severely damaged due to various deficiencies when proper codal provisions are not designed. A study is need to study the behaviour of the RC framed structure under earthquake load to reduce the damage caused by earthquake forces In this investigation a $\mathrm{RC}$ framed building of $\mathrm{G}+20$ storeyed is considered in several seismic zones under different soils as per Indian Standard code IS 1893(part1):2016, using STAAD. Pro V8i as software tool. Finally evaluate the ultimate Base shear using Equivalent static method and Response spectrum method addressing under design forces.
\end{abstract}

\section{Introduction}

RCC encircled structure is actually a get together of pieces, shafts, sections, and establishment entomb related to each other as a unit. The heap move, in such a structure happens from the pieces to the pillars, from the bars to the segments and afterward to the lower sections lastly to the establishment which thusly moves it to the dirt. the ground territory of a R.C.C surrounded structure building is 10 to 12 percent quite that of a heap bearing walled fabricating. Solid development is conceivable with R.C.C confined structures and that they can oppose vibrations, seismic tremors and stuns more successfully than load bearing walled structures. Speed of development for RCC confined structures is progressively fast. The program consequently comprises of the accompanying offices to empower this errand.

Graphical model age utilities even as content toolbased orders for creating the scientific model. Shaft and segment individuals are spoken to utilizing lines. Dividers, chunks and board type elements are spoken to utilizing triangular and quadrilateral limited components. Strong squares are spoken to utilizing block components. These utilities permit the client to form the geometry, appoint properties, arrange cross areas as wanted, administered materials like steel, solid, lumber, aluminium, indicate underpins, apply stacks unequivocally even as have the program produce loads, plan boundaries then on. Examination motors for performing straight flexible and p-delta investigation, limited component investigation, recurrence extraction and dynamic reaction.

Plan buildings for code checking and streamlining of steel, aluminum and lumber individuals. Support figurines for solid pillars, segments, chunks and shear dividers. Plan of shear and second estimations for steel, concrete, timber, aggregates etc individuals.

Result seeing, result confirmation and report age devices for analyzing uprooting charts, bowing second and shear power outlines, shaft, plate also, strong stress, strain and deformations tress forms, then forth.

Fringe apparatuses for exercises like import and fare of the knowledge from and to other generally acknowledged configurations, joins with other wellknown programming projects for balance configuration, steel association plan, then forth.

\footnotetext{
* Corresponding author: author@e-mail.org
} 


\section{Review of Literature}

Akash kumar, Er. Kundan Kulbhushan(2019) : Analyzed a G+21 multi-story fortified solid structure in the seismic zone III with shear divider set at the center of the structure and thought about the pinnacle story removal acquired in Equivalent static technique, Response range strategy, Time history examination utilizing ETABS programming device.( The proposed arrangement is utilized for workmanship display so that there are no inside dividers, overhangs and balances which in a roundabout way decreases the division of harm. The evaluation of cement utilized for the structure is M35andM40 is utilized for the basic segments, for example, subterranean level, ground floor and first floor)

Dipak M. kolekar, Mukund M. pawar(2017) had examined the variety of base shear, story shear and base snapshots of $\mathrm{G}+3, \mathrm{G}+5, \mathrm{G}+7, \mathrm{G}+9$ story structures and looked at between two changed arrangement regions in a few seismic zones according to IS 1893(Part-1): 2002.

In this writing thought about the base shear of the an arrangement with various no accounts and presumed that base shear, story shear and base snapshots of the structure increments with increment in the no. of storeys(height of the structure) and furthermore increments with the expansion in the zone factor(i.e, seismic zone), and most extreme in the seismic zone V.

Chi Nag Choudhary and Dr. P.S Bokare(2017): Analyzed a G+10 multi-story strengthened solid structure utilizing STAAD Pro v8i programming instrument, performed straight equal static strategy and reaction range technique acquired the estimations of pinnacle story shear, Moment in $\mathrm{X}, \mathrm{Y} \& \mathrm{Z}$ headings and Base shear from various modes.

Kurapati manasa and A Srikanth(2017) :Analyzed six $\mathrm{g}+10$ story structures with L/B proportions of $1,0.95$, $0.9,0.85,0.8 \& 0.75$ under all the four seismic zones(i.e, zone II, zone III, zone IV, zone V) and three sorts of soil conditions(i.e, delicate, medium and hard soils) and reasoned that the structure under seismic zone $\mathrm{V}$ in the delicate soil has progressively base shear contrasted with the rest of the zones and soil conditions. Yogitha thripati, Ravi dwivedi(2018) : Performed static and dynamic investigation for the structures of $\mathrm{g}+5, \mathrm{~g}+10$, and $\mathrm{g}+15$ having traditional chunk and level sections with and without shear dividers and thought about the aftereffects of static examination and dynamic examination with and without shear dividers, and inferred that the level pieces with shear dividers have high base shear and practical

Mahesh N Patil, Yogesh N Sonawane(2015): In this paper, the tremor reaction of a balanced multi-celebrated structure is concentrated by manual estimation and by utilizing the product device ETABS 9.7.1.the strategy utilized by ETABS incorporates seismic coefficient technique (I. e, identical static strategy) as suggested by
IS 1983:2002(Part I). given total rules to perform seismic investigation and manual estimation of the $\mathrm{g}+8$ structure and reasoned that there is continuous increment in the base shear with the expansion in the no.storeys

Mahdi Hosseini, N. V. Ramana Rao (2016) In this examination a Forty-story building $(120 \mathrm{~m})$ have been displayed utilizing programming ETABS for quake bande $\mathrm{V}$ in India. It expects to contemplate, conduct of fortified solid structure by leading dynamic analysis(Response range technique) for most fit positions and area of shear divider with opening conditions. Even openings are given in shear dividers legitimate sizes to guarantee least interference to drive move through dividers. Acquired the outcomes, for example, story removals, base shear, story float. Dynamic reactions under zone $\mathrm{V}$ seismic tremor according to IS 1893 (section 1): 2002 have been done.

\section{Analytical Study}

\section{Basic Data for Buildings Model:}

Height : $3.0 \mathrm{~m}$

Total storeys: $\mathrm{G}+20$ storeys

Dimension of Column: 450mm X $230 \mathrm{~mm}$

Dimension of Beam: $230 \mathrm{~mm}$ X $450 \mathrm{~mm}$

Thickness of walls : $230 \mathrm{~mm}$

Soil: Type 2, Medium Soil

Seismic Zone: II

Building Frame Systems: Ordinary MRF

Live Load : $2 \mathrm{KN} / \mathrm{m}^{2}$

Support: Fixed

Table 1. Methodology

\begin{tabular}{|c|c|c|}
\hline S.NO. & $\begin{array}{l}\text { Building } \\
\text { Parameter }\end{array}$ & Description \\
\hline 1 & $\begin{array}{l}\text { Type of } \\
\text { frame }\end{array}$ & SMRF \\
\hline 2 & $\begin{array}{l}\text { Seismic } \\
\text { zone }\end{array}$ & $\begin{array}{l}\text { All zones as per } \\
\text { IS 1893(Part I): } \\
2016\end{array}$ \\
\hline 3 & IF & 1.20 \\
\hline 4 & RRF & 5.0 \\
\hline 5 & $\begin{array}{l}\text { Type of } \\
\text { soil }\end{array}$ & $\begin{array}{l}\text { Hard, Medium, } \\
\text { Soft soils }\end{array}$ \\
\hline 6 & $\begin{array}{l}\text { Damping } \\
\text { ratio }\end{array}$ & $5 \%$ \\
\hline 7 & Load & $2.07 \mathrm{kN} / \mathrm{m}$ \\
\hline $7 \mathrm{a}$ & Dead load & $13.8 \mathrm{kN} / \mathrm{m}$ \\
\hline $7 \mathrm{~b}$ & FL & $3.125 \mathrm{kN} / \mathrm{m}^{2}$ \\
\hline $7 \mathrm{c}$ & LL & $3 \mathrm{KN} / \mathrm{m}^{2}$ \\
\hline 8 & Concrete & $\mathrm{M}-25 \mathrm{~N} / \mathrm{mm}^{2}$ \\
\hline 9 & Steel & $\mathrm{Fe}-415 \mathrm{~N} / \mathrm{mm}^{2}$ \\
\hline
\end{tabular}




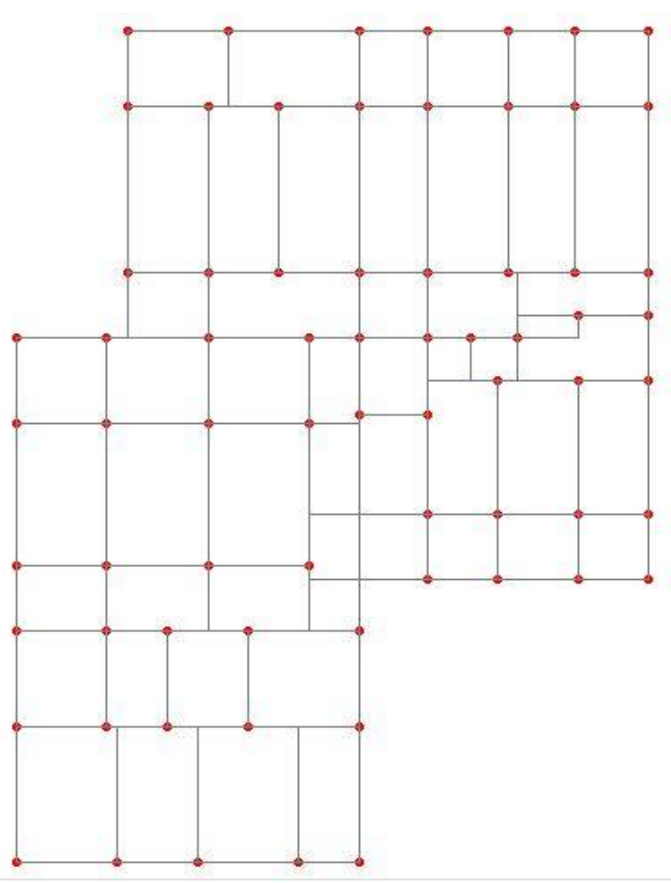

Fig 1. KeyPoints of structure

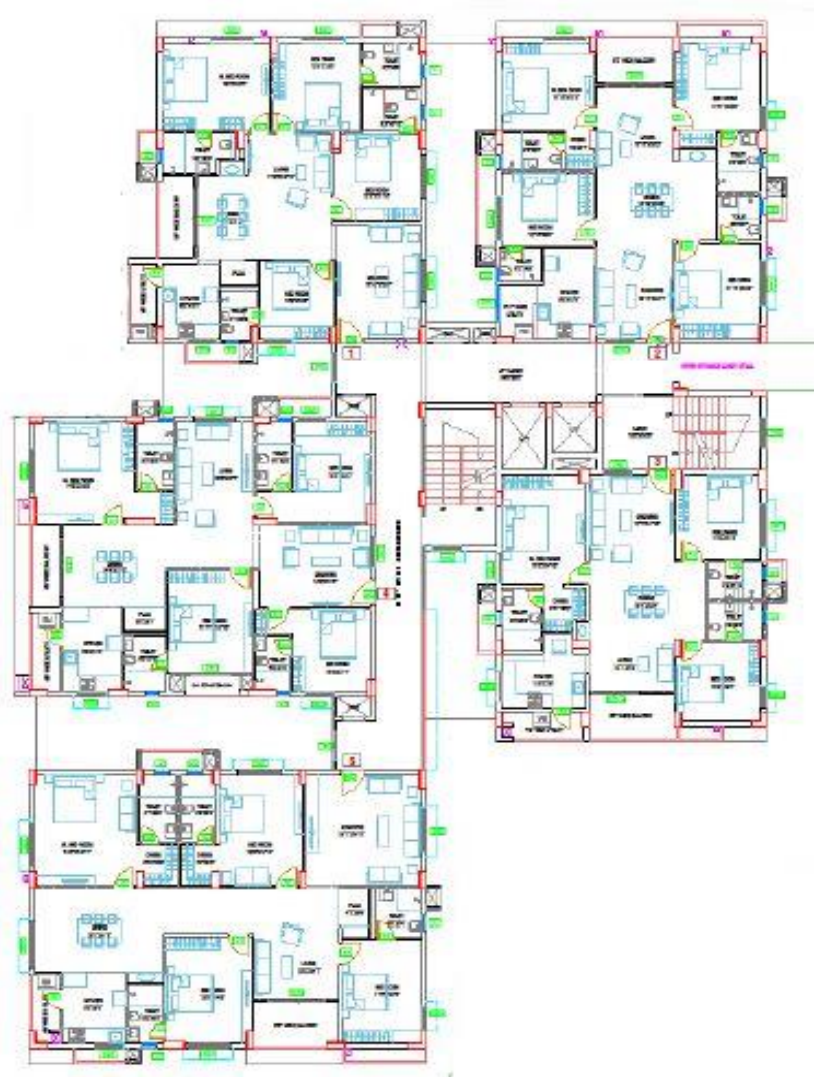

Fig 2. Plan of building

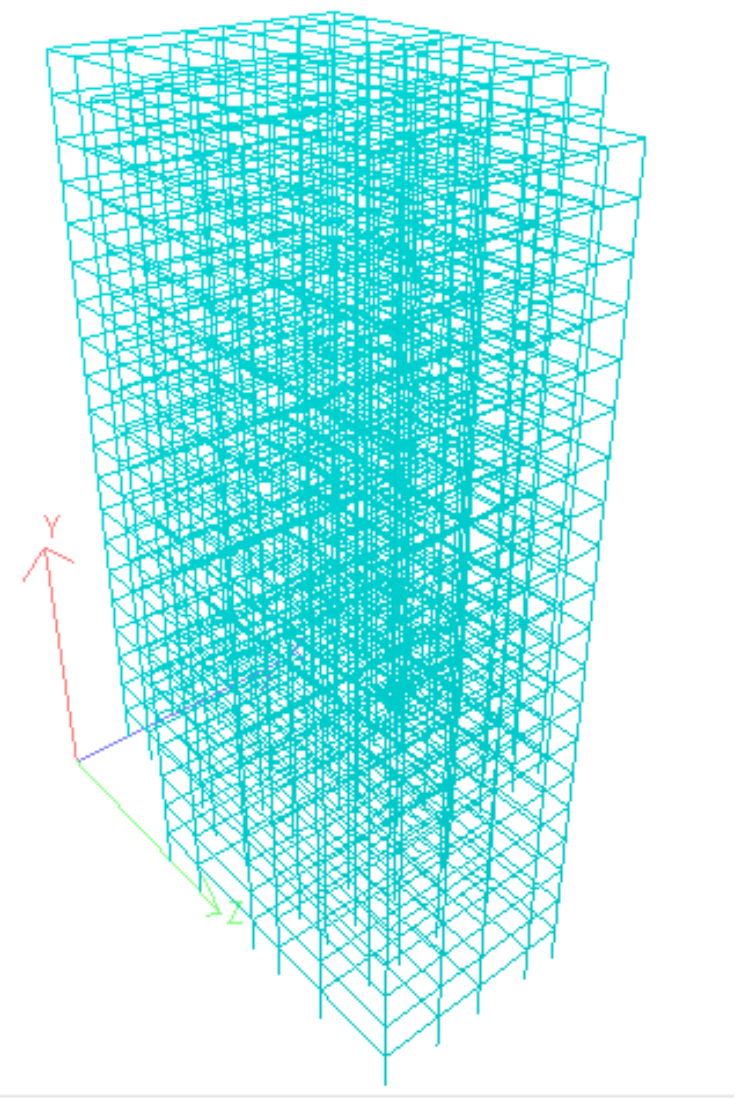

Fig 3. Modelling of structure

\section{Conclusions}

In this investigation, the adjustment in configuration aftereffects of $\mathrm{G}$ plus 20 to several story building modelled utilizing Staad. Pro tool is summed up underneath:

1. Max forces of a G Plus 20 customary structure delivered is $1984.28 \mathrm{kN}$ in Staad. Pro for of loads 1.5 (Self + Dead + Live + EL $)$.

2. Maximum Deformation for individuals from G Plus 20 private structure in 3D axis in Staad .Pro is $0.03 \mathrm{~mm}$, Zero $\mathrm{mm}$ and $0.038 \mathrm{~mm}$ separately According to above information it has been reasoned that the greatest relocation is along $\mathrm{x}$-direction, worth are $29 \mathrm{~mm}$ (in Staad. Pro.) $31 \mathrm{~mm}$ along $\mathrm{x}$-direction.

3. Twisting snapshot of bar part 481 of popular narrative structure utilizing Staad .Pro are 35.94 kN.m for a heap mix of $1.5(\mathrm{DL}+\mathrm{LL}+\mathrm{EL})$. Here there is an addition of Bending Moment by ten percentage that reveals greater fortification are expected.

4. Avoidance of shaft part 481 of popular narrative structure utilizing STAAD.Pro is $2.96 \mathrm{~mm}$ a heap mix of 1.5(Dead L+EL+Live L)

5. Shear force of bar part $480 \mathrm{KN}$ of popular narrative structure utilizing Staad.Pro is $52.50 \mathrm{kN}$.m a heap mix are 1.5 (Dead L +EL + Live L) 


\section{References :}

1. C. Griffith, A Pinto (2000), "Seismic Retrofit of RC Buildings - A Review and Case Study", University of Adelaide, Ispra Italy.

2. S bharat and G Paresh, 2011, "Behaviour of Building Component in Various Zones," IJAES, Vol. 1, Issue 1(Jan. 2011)

3. K Poonam Anil and K G Ashok 2012, "Study of Response of Structural Irregular Building Frames to Seismic Excitations," I J CSEIERD

4. Mohammed Hussain, Y. Kamala Raju "Fitting Infiltration Equations using Double Ring Infiltrometer to Design and Evaluate Irrigation Methods" IJRTE, Volume-8 Issue-4, Nov 2019.

5. Text book of "Highway Engineering "by S.kanna and Justeo.

6. Y. Kamala Raju, N. Tejaswi, S. Anjali Reddy "Reinforced Cement Concrete Cylindrical Shell for Parking Sheds" TEST Engineering \& Management magazine, May -June 2020, Volume 83, Vol. 83, May/June 2020,

7. MSB Jeyakumar, Y. Kamala Raju "Characteristics of Paper brick with Inequitable Substitution of Cement" IJITEE, Vol 8 Issue-12S, Oct 2019, PP 8588

8. Y. Kamala Raju, MSB Jeyakumar "Modulus Of Elasticity On High Performance Glass Fibre RCC Beams With Partial Replacement Of Cement By Silica Fume" IJITEE Vol 8 Issue-10, Aug 2019,

9. Y. Kamala Raju and Rathod Ravinder "Reverse Osmosis Plant Design and Evaluation - A Case Study" IJLTET, Vol.10 Issue 3, May 2018.

10. Y. Kamala Raju, R. Meher Babu and Mohammed. Husssain "Reinforced Cement Concrete Bridge Deck Design of a Flyover with Analysis for Dynamic Response Due to Moving Loads for Urban Development in Transportation Systems - A Case Study" IJERMCE, Vol 3, Issue 2, Feb 2018. PP 121-128.

11. Y. Kamala Raju, N. Harish Kumar (2019)"Strength Performance of Crumb Rubber Concrete ", Volume 7, Issue V, IJRASET Page No 2007-2010.

12. Y. Kamala Raju, R. Meher Babu and Mohd. Husssain (2017)"Autoclaved Aerated and Cellular Fly ash Concrete Blocks for Building Constructions", Proceedings National Conference on Recent Innovations in Civil Engineering (RICE2017) December 15-16, 2017.

13. Y. Kamala Raju, R. Meher Babu, Mohd. Husssain (2018) "Reinforced Cement Concrete Bridge Deck Design of a Flyover with Analysis for Dynamic Response Due to Moving Loads for Urban
Development in Transportation Systems - A Case Study" (IJERMCE), Vol 3, Issue 2, February 2018.

14. Y. Kamala Raju, Venkat Charyulu S, Srikanth T (2019) "Influence of Support Reactions on RCC Building Frames a Computational Method" IJRTE, Vol 8 Issue-3, Sep 2019 PP:4711-4715.

15. MSB Jeyakumar, Y. Kamala Raju (2019) "High Performance Reinforced Concrete Beams with Partial Replacement of Cement Using Silica Fume And Glass Fibre", (IJRAR), Volume.6, Issue 2, Page No pp.44-49, June 2019. 